Joachim Herrmann WEGE ZUR GESCHICHTE 



\section{Joachim Herrmann}

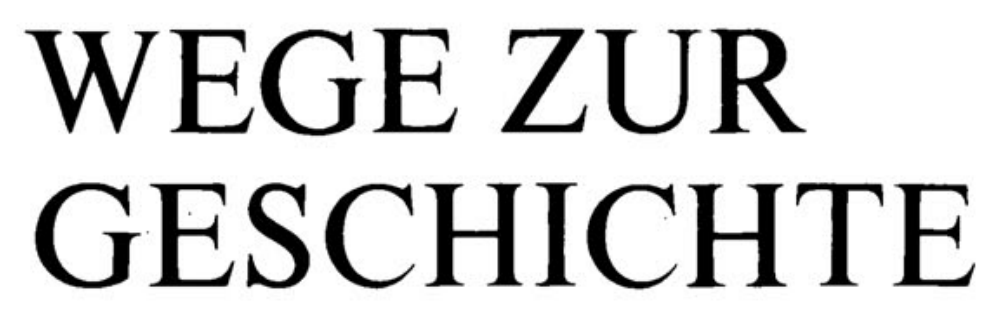

Ausgewählte Beiträge

Herausgegeben von Bernhard Tesche Mit 88 Abbildungen

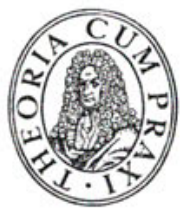

Akademie-Verlag Berlin 1986 
ISBN 3-05-000217-4

Erschienen im Akademie-Verlag Berlin, DDR-1086 Berlin, Leipziger Str. 3-4

(C) Akademie-Verlag Berlin 1986

Lizenznummer : $202 \cdot 100 / 262 / 86$ P 76/86

Printed in the German Democratic Republic

Gesamtherstellung: VEB Druckerei „Thomas Müntzer“, 5820 Bad Langensalza

Schutzumschlag und Einband: Peter Werzlau

LSV 0235

Bestellnummer : 7546887 (6976)

04500 